\title{
DIREITOS HUMANOS DAS PESSOAS COM DEFICIENCIA MENTAL: TRATAMENTO INSTITUCIONAL NO CONTEXTO BRASILEIRO
}

\section{Mariana Dionísio de Andrade ${ }^{1}$}

\section{Resumo}

O objetivo da presente pesquisa consiste em responder a seguinte pergunta: como deve ser o tratamento institucional para a proteção dos direitos humanos de pessoas com deficiência mental no contexto brasileiro? A pesquisa adotou o método descritivo-analítico, com aportes teóricos em bibliografia especializada e análise comparativa. O presente estudo aborda, ainda, uma das mais emblemáticas situações na história da saúde psiquiátrica brasileira; o Hospital Psiquiátrico Colônia, que abrigou centenas de esquecidos e marginalizados sociais, em um sistema de internação cujo tratamento oferecido aos pacientes jamais se compatibilizou com a reinserção proposta, distanciando-se, por completo, das noções mais elementares de proteção dos direitos humanos. Conclui-se que a proteção dos direitos humanos no contexto psiquiátrico brasileiro depende da implementação de políticas públicas consistentes e continuadas, além da nova interpretação da norma atinente à matéria, superando a perspectiva simbólica de mera base retórica de direitos.

Palavras-chave: Políticas Públicas; Pessoa com deficiência mental; Direitos humanos; Hospital Psiquiátrico Colônia; Instituições.

\section{INTRODUÇÃO}

A Constituição da República de 1988, além de estabelecer uma nova interpretação sobre direitos e garantias fundamentais, priorizando a dignidade humana e considerando as relações sociais sob a proposta de um contexto social includente, exerceu, ainda, enorme influência sobre o direito decorrente das relações privadas, baseadas em interesses individuais.

Deve-se considerar a saúde como Direito Humano fundamental e, como todos os direitos, exige a comunhão de esforços entre sociedade e poder público no planejamento e na prestação de serviços e de cuidados.

O primeiro contato com os temas relacionados aos direitos humanos revela, de imediato, a amplitude do instituto e suas implicações sociais. Esta pode ser resumida na conhecida ideia de que os direitos humanos são

\footnotetext{
${ }^{1}$ Pós-Graduanda do Programa de Doutorado em Ciência Política pela Universidade Federal de Pernambuco - UFPE (Bolsista CAPES). Professora da Disciplina Direito Processual Civil. Pesquisadora do Multidoor Courthouse System. Membro associado do Conselho Nacional de Pesquisa e Pós-Graduação em Direito - CONPEDI. Membro do Grupo de estudos sobre Poder Judiciário, Política e Sociedade - PRAETOR / UFPE (Coord. Prof. Dr. Ernani Carvalho). Membro da Comissão de Ensino Jurídico da OAB/CE. E-mail: mariana.dionisio@gmail.com
} 
direitos das pessoas em condição de vulnerabilidade. Mas não apenas isso.

A amplitude dos direitos humanos requer a convicção de que igualdade e dignidade humana são elementos essenciais para o desenvolvimento social. A eficácia jurídica e social desses direitos se apresenta como desafio para o Brasil, assim como para outros países de sistema democrático recente.

Uma das temáticas menos recorrentes na análise do direito atinge uma parcela da população que carece de prestações mínimas pela própria ausência de capacidade ínsita por sua condição: a pessoa com deficiência mental.

O campo das políticas públicas sobre Saúde Mental no Brasil segue as inovações legais sobre o tema, mas ainda deixa a desejar pela ainda esparsa atuação, nos planos municipal, estadual e federal; quanto à formulação de políticas voltadas ao resgate de direitos humanos e fundamentais, especialmente no que diz respeito à promoção de espaços de desenvolvimento e inclusão.

O Brasil, nas últimas décadas, tem implantado políticas públicas decorrentes da teoria norte-americana sobre o conceito de ações afirmativas ou discriminações reversas, ou seja; adoção de meios para se promover a redução de desigualdades por intermédio da construção de um patamar mínimo de igualdade material, que pode ocorrer por meio da atuação estatal e/ ou pela intervenção de instituições.

Entretanto, há de se considerar que para cada política é necessária a realização de um recorte epistemológico específico, com definição de público atendido, resultados esperados e principais direitos a serem resgatados, além de definição e delimitação de custos, bem como determinações estratégicas e planejamento.

Assim, é possível perceber que para cada política implementada, uma série de ações institucionais devem ser arquitetadas para atingir uma finalidade específica, abrangendo uma comunidade determinada e um problema social pontual. Eis o grave problema aqui identificado: há uma inolvidável carência quanto à elaboração de políticas públicas voltadas às pessoas portadoras de debilidade mental, cuja descrição possui previsão constitucional e civil, mas cuja incapacidade condiciona a manifestação de opinião e limita a expressão de vontades íntimas.

Trata-se de um público de considerável abrangência numérica, mas que em contrapartida possui uma assistência ainda insuficiente para a demanda, o que caracteriza uma perspectiva desproporcional entre a profusão de necessidades e o que é promovido em termos de políticas públicas direcionadas, principalmente na construção de rede de serviços de pequena e média complexidade para atendimento psicossocial.

Essa construção depende da articulação de ações entre Ministério da Saúde, Secretaria de Atenção à Saúde, Departamento de Ações Programáticas Estratégicas e Governo Federal, para inclusão das propostas na agenda governamental e avaliação das possibilidades para a decisão, política.

A atenção e formulação de uma agenda governamental que compreenda a implementação de políticas 
públicas depende de uma articulação política que envolva o momento certo, as circunstâncias adequadas, propostas conciliáveis, presença de apelo social e viabilidade financeira das propostas ventiladas.

O texto objetiva uma digressão histórica a partir do estudo de um caso específico de desrespeito aos direitos humanos, ocorrido no Brasil no início do século XX, nas dependências do Hospital Psiquiátrico Colônia, reconhecido popularmente como "o Holocausto brasileiro", por ter sido palco para contumazes violações à dignidade humana, desconsiderando o ser humano ${ }^{2}$ como um elemento de essencial proteção. Esse período merece destaque no presente estudo justamente pelo destaque quanto à situação dos doentes mentais no Brasil, as circunstâncias de marginalização e, principalmente, para fundamentar a elaboração de normas protetivas específicas e políticas públicas mais abrangentes e continuadas para indivíduos nessa condição.

A metodologia foi elaborada com base em estudo descritivo-analítico, com aportes teóricos em referências especializadas, a partir da análise sobre a necessária preocupação das instituições na elaboração e aplicação de políticas públicas voltadas à proteção de direitos humanos e fundamentais das pessoas com deficiência mental.

\section{SOBRE O DEVER DE PROTEÇÃO AOS DIREITOS HUMANOS}

A história dos direitos humanos foi marcada por um intenso conflito de concepções quanto à dignidade humana, que, por essência, deve superar as desigualdades com o objetivo de promoção de melhor adequação social de grupos diversos, de maneira equânime. Aqui, evidencia-se o conceito ocidental e liberal de dignidade humana, conforme enuncia Jorge Miranda (1993, p.169):

Em primeiro lugar, a dignidade da pessoa é da pessoa concreta, na sua vida real e quotidiana; não é de um ser ideal e abstracto. É o homem ou a mulher, tal como existe, que a ordem jurídica considera irredutível e insubstituível e cujos direitos fundamentais a Constituição enuncia e protege. Em todo o homem e em toda a mulher estão presentes todas as faculdades da humanidade.

O componente social-democrático da Declaração Universal dos Direitos Humanos deve ser considerado como conteúdo de vital importância para a materialização de seus postulados, sob o risco de, não o sendo, tornar-se letra despida de efetividade e subsumida à esfera ideológica.

Os Estados-membros devem adotar medidas para coibir violações, individualmente e com a assistência e cooperação internacional, entretanto, nem sempre se verificam atuações pungentes e efetivas por parte dos países

\footnotetext{
2 “[...] supondo que haja alguma coisa cuja existência em si mesma tenha um valor absoluto e que, como fim em si mesma, possa ser o fundamento de determinadas leis, nessa coisa, e somente nela, é que estará o fundamento de um possível imperativo categórico, quer dizer, de uma lei prática. Agora eu afirmo: o homem - e, de uma maneira geral, todo o ser racional - existe como fim em si mesmo, e não apenas como meio para uso arbitrário desta ou daquela vontade. Em todas as suas ações, pelo contrário, tanto nas direcionadas a ele mesmo como nas que o são a outros seres racionais, deve ser ele sempre considerado simultaneamente como fim”. (KANT, 2004, p. 52)
} 
signatários de pactos e tratados internacionais em prol dos direitos humanos.

Os direitos humanos ${ }^{3}$ são um importante instrumento de proteção aos direitos dos cidadãos, tendo o condão de ser protegido internacionalmente, tendo como principais características citadas no excerto aba ixo:

A proteção internacional dos direitos humanos constitui um dos traços mais mar- cantes não
só do Direito Internacional convencional moderno como também, num plano mais vasto,
da evolução do Direito Internacional contemporâneo. E se é certo que muitas convenções se
dirigem diretamente aos Estados, outras há que conferem direitos diretamente aos
indivíduos. A primeira via - a via da mera proteção diplomática - vai sendo cada vez mais
abandonada na medida em que se pretende de fato tornar mais eficazo Direito Internacional
dos Direitos Humanos, acima de tudo porque ela se revela inoperante na defesa do
indivíduo contra o próprio Estado a que ele pertence e que constitui o seu principal
adversário potencial. (PEREIRA; QUADROS, 2002.p. 392)

No estudo dos diversos elementos que compõem os direitos humanos, é possível citar, primeiramente, a historicidade e a cadeia evolutiva dessa ordem de direitos, considerando, além da criação de normas e instituições, a realidade fática da sociedade e os valores éticos e morais que dela emergem.

Cumpre ressaltar que a evolução histórica dos direitos humanos se dá por intermédio da dinamogênesis, isto é, o contexto social em que a comunidade reconhece como imperioso um valor que fundamenta o direito humano, sob uma perspectiva heterogênea e multicultural. (DOUZINAS, 2009). Este valor concebe uma nova gradação à dignidade da pessoa humana, que supõe uma nova orientação e um novo conteúdo, como consequência da conexão deste com o parâmetro solidário atual, conferindo funcionalidade ao próprio Direito. (SILVEIRA; ROCASOLANO, 2010).

A realidade brasileira é incomparável quando evidenciada ao lado de outros sistemas democráticos, principalmente porque o contexto social em que se propõe a realização de direitos humanos nunca foi linear.

O Brasil convive de maneira resignada com a marginalização, violação da dignidade humana e desigualdade social, razão pela qual não é possível considerar o cumprimento e valoração de direitos humanos na mesma medida de ponderação que os demais Estados-membros signatários da Declaração Universal dos Direitos Humanos.

Verificando-se a relação direta entre as circunstâncias sociais e o conteúdo dos direitos, torna-se essencial analisar se o universalismo expresso pelo Direito Internacional dos Direitos Humanos, na qualidade de elemento transversal à Declaração Universal dos Direitos Humanos, é compatível com a diversidade cultural encontrada nos países signatários e as consequentes variações quanto ao conteúdo da dignidade humana como concepção

\footnotetext{
${ }^{3} \mathrm{~A}$ proposta de vislumbrar os direitos humanos como um instrumento de proteção internacionalmente reconhecido não retira da análise a percepção de que essa ordem de direitos encontra um lugar pouco confortável no texto legal, na medida em que se torna discurso jurídico positivado dentro uma ótica unificada e padronizada, que talvez não alcance a realidade individual, violando a perspectiva de justiça material. (DOUZINAS, 2009). O conteúdo dos direitos humanos segue além da esfera normativa, pois deixa de existir se não observar as demandas individuais de cada sujeito, tornando-se, talvez, sem efeito pela cristalização de propostas normativas para a positivação de uma ordem de direitos que deixa de existir se não for aplicado.
} 
integradora de valores sociais.

O que se percebe, em última análise, é que onde não houver respeito pela vida e pela integridade física e moral do ser humano, onde as condições mínimas para uma existência digna não forem asseguradas, onde não houver limitação do poder, enfim, onde a liberdade e a autonomia, a igualdade (em direitos e dignidade) e os direitos fundamentais não forem reconhecidos e minimamente assegurados, não haverá espaço para a dignidade da pessoa humana e esta (a pessoa), por sua vez, poderá não passar de mero objeto de arbítrios e injustiças. (SARLET, 2007, p. 125).

No Brasil, o elemento circunstancial para a elaboração de normas sobre direitos humanos supõe a existência de uma relação tridimensional do Direito na construção do conteúdo da dignidade humana. Essa relação tridimensional reúne fato, valor e norma, coexistindo em uma unidade concreta. Onde quer que haja um fenômeno jurídico, há um fato. O valor consiste no significado atribuído ao fato, enquanto a norma representa a relação ou medida que integra o fato ao valor. Trata-se de um caminho essencial a ser seguido para conferir validade à norma jurídica, que se sustenta no fundamento de ordem axiológica, eficácia social e validade formal, que significa obediência aos trâmites legais. (REALE, 2012).

Assim, é possível dizer que a realidade jurídica brasileira exige a presença desses três elementos para a consolidação da legitimidade de uma lei internacional. Ao que parece, todos os Estados que estão limitados pela lei internacional se tornam automaticamente civilizados por adotar medidas universalizantes para a proteção da dignidade, pelo fato de terem manifestado adesão à Declaração Universal dos Direitos Humanos, entretanto, esse manto de nobreza nem sempre é compatível com os esforços e interesses de cada Estado, simplesmente porque a legislação é um simulacro do que deve ser, e não do que é

Mas os direitos humanos não fazem parte de um discurso indeterminado, que dispensa o pragmatismo. Pelo contrário, pode evidenciar a história das fragilidades das lideranças políticas e jurídicas na proteção de direitos em âmbito local (a exemplo da realidade brasileira, que ratificou a adesão à Convenção Americana de Direitos Humanos, subscrita durante a Conferência Especializada Interamericana de Direitos Humanos, apenas 23 anos após sua assinatura em San José, Costa Rica). E as especificidades de cada população devem ser observadas de maneira cautelosa, porque, apesar de universalizantes, os direitos humanos não supõem tratamento genérico.

Pelo contrário, atuam na tentativa de regulamentar e resguardar direitos individuais. No caso específico das populações excluídas, a exemplo das pessoas com transtornos mentais, há ainda um longo caminho a seguir no que diz respeito à realização de direitos elementares, como o acesso à saúde, dignidade, inclusão social e proteção aos maus tratos.

Em termos práticos, a materialização dos direitos humanos e fundamentais ocorrerá processualmente, em especial, pela utilização do processo cooperativo, em que todos os sujeitos do processo colaboram para a mais plena execução da justiça.

O princípio da cooperação, destacado no diploma processual civil, reforçado pelo princípio da razoável 
duração do processo expressa no art. 5\%, LXXVIII da Constituição brasileira de 1988 e trasladado da tradição jurídica europeia, não é capaz, por si, de proclamar a pacificação social, o fim da pretensão resistida e a resolução dos problemas do Judiciário brasileiro, mas possui o grande mérito de promover a valorização de todos os envolvidos na relação jurídico-processual, inclusive, do jurisdicionado.

A disposição legal sobre a necessária cooperação entre todos os órgãos do Poder Judiciário e demais instituições na persecução dos direitos, amplia definitivamente a envergadura do instituto, que não deve ser observado apenas no âmbito forense, mas em toda a integralidade da esfera judicial.

Cabe aos sujeitos do processo contribuir com o desenvolvimento da demanda. Sobre o assunto, enunciam Cleber Francisco Alves e Marília Gonçalves Pimenta (2004, p. 24), que "de nada adianta assegurar a observância do processo democrático na fase de produção do Direito se as autoridades encarregadas de interpretá-lo e de executá-lo não estiverem comprometidas com a realização da vontade popular", que se denota presente na razão de ser da própria norma jurídica.

Compete ao Poder Judiciário, aos órgãos competentes da Administração Pública, Ministério da Saúde, Secretaria de Atenção à Saúde, Departamento de Ações Programáticas Estratégicas e profissionais habilitados, a condução coordenada de ações em prol da defesa de direitos elementares ao indivíduo, mas que, apesar da previsão de envergadura constitucional, carecem de alcance generalizante e, em termos práticos, de efetividade.

Trata-se de um compromisso conjunto de instituições, que deve primar pela diligência e resolutividade de questões urgentes, tornando-se inadmissível conceber um estado de coisas em que direitos humanos deixam de ser cumpridos e a Constituição, por conseguinte, vilipendiada.

\section{O ANTIMODELO DE POLITICA DE SAÚdE PÚBLICA NO BRASIL: O HOSPITAL PSIQUIÁTRICO COLÔNIA}

Fundado em 12 de outubro de 1903, na cidade de Barbacena, no Estado de Minas Gerais / Brasil, o Hospital Colônia de Barbacena fazia parte de um grupo de sete hospitais psiquiátricos, também conhecido popularmente como Hospício Colônia. Atualmente, apenas três estão em funcionamento.

O hospital foi construído na sequência da criação da Assistência aos Alienados no Estado de Minas Gerais em 1900. Junto ao hospital, com uma área aproximada de 8 mil metros quadrados que comportavam 16 pavilhões, foi construído na mesma época um cemitério, designado de "Cemitério da Paz". Os internos do Hospital Psiquiátrico Colônia eram conduzidos em um vagão de trem, compulsoriamente. Ao chegarem, tinham as cabeças raspadas, as roupas arrancadas e os documentos retidos, pois teriam a identidade e todas as referências familiares substituídas por um número de identificação. Entretanto, o Hospital Colônia de Barbacena (também conhecido como "Cidade dos Loucos") não tinha como pacientes apenas pessoas com transtornos mentais. 
Na verdade, 70\% dos pacientes não tinham qualquer diagnóstico de doença mental, mas haviam sido enviados para o Hospital Colônia por pertencerem a uma classe de excluídos sociais, como prostitutas, alcoólatras, homossexuais, militantes políticos, mendigos, crianças abandonadas, jovens delinquentes e mulheres grávidas com a paternidade desconhecida (usualmente estupradas por seus patrões) ou jovens que haviam perdido a virgindade antes do casamento. (ARBEX, 2013).

No momento da chegada, as vítimas eram recepcionadas com a realidade de um hospital psiquiátrico em que toda a privacidade e individualidade eram desconhecidas, de maneira a propiciar o cancelamento total do passado e início do aniquilamento social daqueles indivíduos.

É incensurável a permanência da concepção kantiana no sentido de que a dignidade da pessoa humana, sendo esta considerada como fim e não como meio, repudia toda e qualquer espécie de coisificação e instrumentalização do ser humano, levando à condenação de muitas práticas de aviltamento da pessoa à condição de coisa. (SARLET, 2007, p. 35).

Eles eram reduzidos a um irreversível estado de torpor, sem qualquer esperança por sobrevivência ou acesso aos direitos individuais elementares. As visitas por familiares eram permitidas; mas não eram colocadas em prática de acordo com as disposições vigentes. A convivência forçada entre os internos tornou quase impossíveis quaisquer formas de autonomia social.

No momento em que os diferentes indivíduos são excluídos da sociedade no intuito de serem normatizados e disciplinados de acordo com os valores de ordem vigente, perdem o controle de seus corpos, passam a nao mais terem como definir vida, alimentação, assim como suas diferentes necessidades fisiológicas. (SANT’ANNA, 2001). Seguem alguns relatos de estórias vividas no Hospital Psiquiátrico Colônia, como demonstração do que aqui é relatado:

Sônia Maria da Costa, hoje com aproximadamente 65 anos (não se sabe a idade exata porque os documentos foram descartados na data de sua internação), cresceu sozinha no hospital. Foi vítima de todos os tipos de violação. Sofreu agressão física, tomava choques diários, ficou trancada em cela úmida sem um único cobertor para se aquecer e tomou as famosas injeções de 'entorta', que causavam impregnação no organismo e faziam a boca encher de saliva. Deixada sem água, bebia a própria urina para matar a sede. Era mergulhada em uma banheira com fezes, como castigo às pessoas que não se enquadravam às regras do Hospital. Em um dia de fúria e dor, arrancou 2 dentes com um alicate, para não sentir mais a dor durante as sessões de eletrochoque. Passou as próprias fezes no corpo enquanto estava grávida, para evitar que seu filho fosse roubado pelos funcionários.

[...]

Maria Auxiliadora de Souza, enfermeira, trabalhou no Hospital Colônia por sete meses. Em 13 de novembro de 1978, no mesmo ano de sua contratação, a enfermeira pediu desligamento de suas funções. Levou na lembrança a expressão apavorada do menino de 14 anos que puxou sua saia, implorando para que ela impedisse o eletrochoque iminente. 'Não deixe que façam isso comigo, enfermeirinha!'. Foi em vão. Maria Auxiliadora nada pôde fazer. De longe, assistiu o menino se debatendo, já que as descargas elétricas provocam convulsão. Quando a boca do garoto começou a sangrar, ela saiu de perto. (ARBEX, 2013, p. 
$52 / 92)$.

O tratamento desumano era característico da internação, que não realizava distinção entre homens e mulheres, deixados nus e em convivência mista durante todo o período de internação, o que gerava um ambiente de profunda promiscuidade entre os internos e estupros, estes cometidos pelos funcionários.

Os pacientes, não raro, morriam de frio ou de fome e, sem acesso às condições mínimas de saúde ou higiene, bebiam água do esgoto ou urina. As torturas, igualmente realizadas por funcionários, ocorriam periodicamente e as cirurgias de lobotomização eram realizadas de modo quase artesanal. Crianças, adultos e idosos não possuiam tratamento diferenciado, e todos se igualavam no completo abandono.

Trata-se a lobotomia de procedimento cirúrgico utilizado em pacientes de instituições asilares brasileiras, no período compreendido entre 1936 e 1956. Também chamadas de psicocirurgias, consistiam em intervenções que objetivavam desligar os lobos frontais direito e esquerdo de todo o encéfalo, visando modificar comportamentos ou curar doenças mentais. No Brasil, a técnica foi adotada até 1956, passando a ferir o Código de Nuremberg, de 1947, concebido para regulamentar e conter os abusos da experimentação médica em seres humanos ocorridos durante a Segunda Guerra Mundial. (MASIERO, 2010, on line).

Nos períodos de maior lotação, contabilizavam-se 16 óbitos por dia. Os corpos eram vendidos para faculdades de Medicina ou, quando não havia compradores, eram decompostos em ácido, no pátio central do Hospício Colônia, em frente aos outros internos ${ }^{4}$, como mecanismo de controle e contenção pelo terror. As violações ocorridas não eram desconhecidas pelas autoridades políticas, entretanto, nada foi feito. Sobre o tema, é necessário destacar:

Muitos contam que desejaram denunciar o sistema, mas não havia quem se dispusesse a ouvir. Vinte e oito presidentes / governadores e interventores federais do Estado de Minas Gerais revezaram o poder entre 1903 e 1980. Outros dez diretores comandaram a instituição nesse período, alguns por mais de vinte anos, como o médico Joaquim dutra, o primeiro dirigente. Em 1961, o presidente Jânio Quadros colocou o aparato governamental a serviço da instituição para reverter 'o calamitoso nível de assistência dada aos enfermos'. Deputados de Minas Gerais criaram comissões para discutir a situação do Hospital Colônia. Nenhum deles foi capaz de fazer os abusos cessarem. (ARBEX, 2013, p. 43).

A falta de interesse das autoridades políticas e jurídicas na situação dos pacientes do Hospital Colônia evidencia a inexistência de políticas públicas de repressão ao indigno tratamento dado às vítimas do hospício, revelando a dimensão do problema que envolve as normas que regulamentam o tratamento manicomial no Brasil.

\footnotetext{
${ }^{4} \mathrm{O}$ ambiente de terror que cercava o interior do Hospício Colônia evidenciava práticas medievais de tortura e a utilização de choques elétricos para o controle dos pacientes, sem qualquer tipo de recomendação médica ou finalidade terapêutica. Houve momentos em que os eletrochoques eram tão fortes que a sobrecarga derrubava a rede de energia do Município de Barbacena. As crianças geradas durante a internação eram roubadas de suas mães pela equipe de funcionários e muitas mulheres, para evitarem a violência sexual, colocavam fezes por toda a extensão do corpo, diariamente, para não serem tocadas. Em 1961, o fotógrafo brasileiro Luiz Alfredo (jornal O Cruzeiro), ao fotografar o Hospital Colônia, enunciou que "Aquilo não é um acidente, mas um assassinato em massa”. Em 1979, o psiquiatra italiano Franco Basaglia, pioneiro na luta pelo fim dos manicômios, esteve no Brasil e
} 
Hoje, no Cemitério da Paz, construído ao lado do Hospital Psiquiátrico Colônia e desativado em 1980, jazem os corpos de 60 mil excluídos sociais, assassinados por crime de lesa-humanidade.

Há um elemento moral de fundamental importância no tratamento de pessoas com distúrbios mentais, que exige reconhecimento quanto à necessária aptidão dos profissionais envolvidos no tratamento e persistência quanto à sua continuidade. (MASIERO, 2010).

Entretanto, quando a internação psiquiátrica ocorre sem a atenção aos elementos essenciais de respeito à dignidade humana, os indivíduos se tornam vítimas da própria sorte, deixam de possuir a condição humana e se transformam em indicadores desumanizados de violência.

Trata-se o Hospital Psiquiátrico Colônia - que teve a última cela desativada apenas em 1994 - de um difícil capítulo da história da saúde pública no Brasil, que condenou milhares de pessoas à morte lenta e indigna, afrontando direitos humanos. Mas a história não pode ser esquecida, principalmente porque trata de pessoas já tradicionalmente esquecidas pela legislação internacional, pela própria condição de incapacidade plena para os atos da vida civil.

O Brasil abrigou um campo de concentração disfarçado de hospital psiquiátrico, o que justificou o abuso e tortura de milhares de pacientes, e a história pouco conhecida evidencia que a realidade manicomial deve ser continuamente revisitada, sob o risco de novas atrocidades voltarem a ocorrer. (RICOEUR, 1995).

\section{O PASSADO QUE NÃO DEVERIA SER ESQUECIDO: A FORÇA NORMATIVA COMO ELEMENTO DE RESGATE DOS DIREITOS HUMANOS}

A partir da segunda metade do século XX, impulsionada principalmente pelo pioneiro da psiquiatria humanizada, Franco Basaglia ${ }^{5}$, psiquiatra italiano, inicia-se o movimento de ruptura com o tratamento conferido aos pacientes com problemas mentais pelas instituições psiquiátricas. Esse movimento inicia-se na Itália, mas tem repercussões em todo o mundo e muito particularmente no Brasil. Iniciou-se o movimento da luta antimanicomial e Reforma Psiquiátrica no Brasil, profundamente orientados pela defesa dos direitos humanos e resgate da cidadania, institutos tradicionalmente desconhecidos quando a titularidade pertence a pessoas com transtornos mentais.

A ideia central da Reforma Psiquiátrica transcende a denúncia dos casos de violação de direitos e propõe

conheceu o Hospício Colônia. Em seguida, convocou uma coletiva de imprensa, na qual afirmou: "Estive hoje em um campo de concentração nazista. Em lugar nenhum do mundo presenciei uma tragédia como esta”. (ARBEX, 2013).

${ }^{5}$ Um dos psiquiatras mais discutidos no mundo, em função dos trabalhos que desenvolvia na Itália, em 1961 deixou a Universidade de Pádova para dirigir o Hospital Psiquiátrico de Gorizia. Acabou com as medidas institucionais de repressão, criou condições para reuniões entre médicos e pacientes e devolveu ao doente mental a dignidade de cidadão. Seu livro 'A Instituição Negada' é considerado uma obra-prima da Psiquiatria contemporânea. Visitou o Brasil na década de 70, tornando-se uma figura emblemática na questão da luta antimanicomial brasileira. (BRASIL, Ministério da Saúde, 2005, on line). 
a construção de uma rede de serviços e estratégias territoriais e comunitárias, profundamente solidárias e inclusivas.

A Proposta de Reforma Psiquiátrica e política de saúde mental no Brasil tem o apoio do Ministério da Saúde do Brasil, que atua em favor da mudança dos modelos de atenção e gestão nas práticas de saúde, defesa da saúde coletiva, equidade na oferta dos serviços, e protagonismo dos trabalhadores e usuários dos serviços de saúde nos processos de gestão e produção de tecnologias de cuidado, inscrita num contexto internacional de mudanças pela superação da violência asilar. Fundado, ao final dos anos 70, na crise do modelo de assistência centrado no hospital psiquiátrico, por um lado, e na eclosão, por outro, dos esforços dos movimentos sociais pelos direitos dos pacientes psiquiátricos, o processo da Reforma Psiquiátrica brasileira é maior do que a sanção de novas leis e normas e maior do que o conjunto de mudanças nas políticas governamentais e nos serviços de saúde. (BRASIL, Ministério da Saúde, 2005, on line).

Trata-se de um processo político e social complexo, composto de atores e instituições de diferentes origens, a partir da mobilização dos profissionais da saúde mental e dos familiares de pacientes com transtornos mentais, que pretendem modificar a visão institucional sobre o tratamento dos pacientes e, principalmente, sua inserção como indivíduos detentores de direitos.

A mobilização de lideranças políticas conduziu a revisão legislativa proposta pelo então Deputado Federal Paulo Delgado por meio do Projeto de Lei no 3.657 de 1989, que impulsionou o conteúdo normativo da Reforma Psiquiátrica Brasileira. Até esse momento, ainda prevalecia no país o Decreto Presidencial no 24.559 de 1934, que previa o recolhimento de pacientes em hospitais psiquiátricos “mediante simples atestado médico", que poderia ser solicitado por qualquer pessoa.

Em 1990, o Brasil tornou-se signatário da Declaração de Caracas que propôs a reestruturação da assistência psiquiátrica, e, em $1991^{6}$, o Projeto de Lei no 3.657 foi remetido ao Senado Federal e distribuído à Comissão de Assuntos Especiais. O texto somente foi aprovado em 1999 e enviado à Câmara dos Deputados. Em 2001, após doze anos de tramitação no Congresso Nacional, é aprovada a Lei Federal no 10.216 que dispõe sobre a proteção e os direitos das pessoas com transtornos mentais e redireciona o modelo assistencial em saúde mental7. (BRASIL, Ministério da Saúde, 2005, on line). Conforme descreve Daniela Arbex (2013, p. 227):

\footnotetext{
${ }^{6}$ Provavelmente sob a influência da Resolução no 46/119 de 17 de dezembro de 1991, aprovada pela Assembleia Geral da ONU sobre a proteção das pessoas com doenças mentais e a melhoria da assistência à saúde mental, que representou um marco no campo dos direitos das pessoas com doenças mentais, por manifestar a importância quanto à assistência a um único grupo de doenças.

7 'Quando a nova legislação foi implantada no Brasil, havia mais de 50 mil leitos em hospitais psiquiátricos, conforme dados do Ministério da Saúde. Dez anos depois, os leitos somavam pouco mais de 30 mil. Nesse período, 45 hospitais psiquiátricos foram desativados. Ainda restam 200'. (ARBEX, 2013, p. 227).
} 
Quando a nova legislação foi implantada no Brasil, havia mais de 50 mil leitos em hospitais psiquiátricos, conforme dados do Ministério da Saúde. Dez anos depois, os leitos somavam pouco mais de 30 mil. Nesse período, 45 hospitais psiquiátricos foram desativados. Ainda restam 200.

Tem origem a Política de Saúde Mental, que se destina a garantir direitos ao paciente com transtorno mental em serviços substitutivos aos hospitais psiquiátricos, superando a proposta das internações de longa permanência que tratam o paciente de maneira degradante e sob exclusão social, substituindo essa forma arcaica de tratamento pela internação em hospitais gerais, consolidando a ideia da viabilidade da reabilitação psicossocial por meio da inserção pelo trabalho, da cultura e do lazer. Sobre a legislação em comento, é necessário destacar:

Lei $n^{\circ} 10.216 / 2001$, que dispõe sobre a proteção e os direitos das pessoas portadoras de transtornos mentais e redireciona o modelo assistencial em saúde mental.

$[\ldots]$

Art. $2^{\circ}$ Nos atendimentos em saúde mental, de qualquer natureza, a pessoa e seus familiares ou responsáveis serão formalmente cientificados dos direitos enumerados no parágrafo único deste artigo.

Parágrafo único. São direitos da pessoa portadora de transtorno mental:

I - ter acesso ao melhor tratamento do sistema de saúde, consentâneo às suas necessidades;

II - ser tratada com humanidade e respeito e no interesse exclusivo de beneficiar sua saúde, visando alcançar sua recuperação pela inserção na família, no trabalho e na comunidade;

III - ser protegida contra qualquer forma de abuso e exploração;

IV - ter garantia de sigilo nas informações prestadas;

$\mathrm{V}$ - ter direito à presença médica, em qualquer tempo, para esclarecer a necessidade ou não de sua hospitalização involuntária;

VI - ter livre acesso aos meios de comunicação disponíveis;

VII - receber o maior número de informações a respeito de sua doença e de seu tratamento; VIII - ser tratada em ambiente terapêutico pelos meios menos invasivos possíveis;

IX - ser tratada, preferencialmente, em serviços comunitários de saúde mental.

Art. 3ํ É responsabilidade do Estado o desenvolvimento da política de saúde mental, a assistência e a promoção de ações de saúde aos portadores de transtornos mentais, com a devida participação da sociedade e da família, a qual será prestada em estabelecimento de saúde mental, assim entendidas as instituições ou unidades que ofereçam assistência em saúde aos portadores de transtornos mentais.

$[\ldots]$

Art. 10. Evasão, transferência, acidente, intercorrência clínica grave e falecimento serão comunicados pela direção do estabelecimento de saúde mental aos familiares, ou ao representante legal do paciente, bem como à autoridade sanitária responsável, no prazo máximo de vinte e quatro horas da data da ocorrência.

Art. 11. Pesquisas científicas para fins diagnósticos ou terapêuticos não poderão ser realizadas sem o consentimento expresso do paciente, ou de seu representante legal, e sem a devida comunicação aos conselhos profissionais competentes e ao Conselho Nacional de Saúde.

Art. 12. O Conselho Nacional de Saúde, no âmbito de sua atuação, criará comissão nacional para acompanhar a implementação desta Lei. $[\ldots]$

Entretanto, apesar da enorme modificação no cenário da internação psiquiátrica brasileira, esse ainda há lacunas a serem supridas. Por exemplo, deve-se considerar que a legislação penal aplicável à pessoa com transtorno mental em conflito com a lei ainda é incompatível com a Lei no 10.216/2001, Decreto n 3.956/2001 (Promulga 
a Convenção Interamericana para a Eliminação de Todas as Formas de Discriminação contra as Pessoas Portadoras de Deficiência) e Convenção sobre os Direitos das Pessoas com Deficiência (Decreto nº 6949 de 25 de agosto de 2009, que promulga a Convenção Internacional sobre os Direitos das Pessoas com Deficiência e seu Protocolo Facultativo, assinados em Nova York, em 30 de março de 2007), incorporada ao ordenamento com status de Emenda Constitucional.

Por exemplo, é necessário citar a figura do inimputável ${ }^{8}$ com periculosidade social, prevista no artigo 26 do Código Penal brasileiro, caracterizada pelo indivíduo inteiramente incapaz de compreender a dimensão do fato típico e antijurídico cometido.

O artigo 97, da mesma lei, impõe a aplicação de Medidas de Segurança de internação, ou seja, uma sanção penal com caráter preventivo e curativo aos inimputáveis que praticaram crimes cuja penalidade é a reclusão.

Assim, é clara a existência de conflito de interpretação entre as normas, pois o Código Penal brasileiro requer internação se o crime for apenado com reclusão, contrariamente ao previsto pela Lei no $10.216 / 2001$, que indica a internação somente se não houver outro tratamento terapêutico possível.

Aqui, cumpre destacar a ideia de Foucault no que diz respeito à punição pela reclusão (inserindo no contexto da punição ao doente mental): 'A ideia de uma reclusão penal é explicitamente criticada por muitos reformadores. Porque é incapaz de responder à especificidade dos crimes. Porque é desprovida de efeito sobre o público. Porque é inútil à sociedade, até nociva: é cara, mantém os condenados na ociosidade, multiplica-lhes o vício'. (FOUCAULT, 2012, p. 14).

Para sanar o referido conflito, o Conselho Nacional de Justiça do Brasil, por meio do artigo 17, da Resolução no 113/2010, dispôs que o juiz competente para a execução da medida de segurança, sempre que possível, buscará políticas antimanicomiais, adotando a sistemática da Lei no 10.216/200 1 .

É necessário observar que, diante da ocorrência de um crime praticado por pessoa com transtorno mental, a definição da espécie de Medida de Segurança cabível, a partir de uma interpretação do Código Penal brasileiro em harmonia com o disposto na Lei $n^{\circ}$ 10.2106/01, implica na avaliação pormenorizada da periculosidade e do melhor tratamento possível.

Apesar dessa evolução no plano normativo, nem sempre há meios materiais para concretização desses direitos, visto que incorrem os seguintes fatores: abandono familiar, falta de preparo das unidades prisionais,

\footnotetext{
${ }^{8}$ Código Penal brasileiro de 1940. Art. 26. 'É isento de pena o agente que, por doença mental ou desenvolvimento mental incompleto ou retardado, era, ao tempo da ação ou da omissão, inteiramente incapaz de entender o caráter ilícito do fato ou de determinar-se de acordo com esse entendimento. (Redação dada pela Lei no 7.209, de 11.7.1984).
} 
ausência de planejamento estratégico do Estado brasileiro na elaboração de políticas públicas específicas para as populações manicomiais em conflito com a lei e o preconceito social, que reduz drasticamente qualquer possibilidade de reinserção.

\section{POLÍTICAS PÚBLICAS E SAÚDE MENTAL NO BRASIL: EM BUSCA DA RAZÃO}

Para edificar uma cultura de valorização do indivíduo por meio da consolidação dos direitos humanos, há de se encarar a materialização de direitos sob uma perspectiva universalizante, generalizante quanto à abrangência e aplicabilidade das prerrogativas da população, principalmente, quando o enfoque se concentra nas pessoas com transtornos mentais, cuja vulnerabilidade é percebida e sentida por todo o núcleo familiar.

$\mathrm{Na}$ esteira de evolução das políticas de inclusão e proteção à pessoa com transtornos mentais, foi reformulada a ideia dos Centros de Atenção Psicossocial (CAPS), regulamentados pela Portaria no 3.088 de 23 de dezembro de 2011 e dispostos como mecanismos de atenção específica.

Trata-se de uma política pública incremental (LINDBLOM, 2009), visto que o sistema CAPS já existia, entretanto, sem a capilaridade e abrangência interdisciplinar que possui hoje. Segundo relatório do Ministério da Saúde sobre Saúde Mental do SUS: "O primeiro Centro de Atenção Psicossocial (CAPS) do Brasil foi inaugurado em março de 1986, na cidade de São Paulo: Centro de Atenção Psicossocial Professor Luiz da Rocha Cerqueira, conhecido como CAPS da Rua Itapeva.

A criação desse CAPS e de tantos outros, com outros nomes e lugares, fez parte de um intenso movimento social, inicialmente de trabalhadores de saúde mental, que buscavam a melhoria da assistência no Brasil e denunciavam a situação precária dos hospitais psiquiátricos, que ainda eram o único recurso destinado aos usuários portadores de transtornos mentais. Nesse contexto, os serviços de saúde mental surgem em vários municípios do país e vão se consolidando como dispositivos eficazes na diminuição de internações e na mudança do modelo assistencial.

Os NAPS/CAPS foram criados oficialmente a partir da Portaria GM 224/92 e eram definidos como "unidades de saúde locais/regionalizadas que contam com uma população adstrita definida pelo nível local e que oferecem atendimento de cuidados intermediários entre o regime ambulatorial e a internação hospitalar, em um ou dois turnos de quatro horas, por equipe multiprofissional”. (Relatório do Ministério da Saúde, 2010, on line).

Considerando a necessidade de que o Sistema Único de Saúde ofereça uma rede de serviços de saúde mental integrada, articulada e efetiva nos diferentes pontos de atenção, a referida Portaria agrega União, Estados e

Parágrafo único - A pena pode ser reduzida de um a dois terços, se o agente, em virtude de perturbação de saúde mental ou por desenvolvimento mental incompleto ou retardado não era inteiramente capaz de entender o caráter ilícito do fato ou de determinar-se de acordo com esse entendimento. [...]' 
Municípios para a realização de políticas públicas voltadas à proteção de direitos humanos e fundamentais.

$\mathrm{O}$ ato de constituir uma rede de auxílio psicossocial, exige a necessária a reunião de todos os recursos afetivos, sanitários, sociais, econômicos e culturais que sejam hábeis para potencializar as equipes de saúde nos esforços de cuidado e reabilitação, nas medidas possíveis de reinserção. A articulação interdisciplinar, que envolve psicólogos, psiquiatras, assistentes sociais e profissionais de diversas áreas, amplia o foco de atendimento para além do paciente: supõe a participação familiar no processo de reinserção. Cumpre destacar a rede de abrangência e cobertura dos Centros de Atenção Psicossocial (CAPS), exposta no quadro abaixo, com progressão do período entre 2002 até 2010 :

Tabela 1 - Indicador de Cobertura CAPS/100.000 habitantes por ano e UF. Brasil (20022010)

\begin{tabular}{|c|c|c|c|c|c|c|c|c|c|}
\hline Região/UF & 2002 & 2003 & 2004 & 2005 & 2006 & 2007 & 2008 & 2009 & 2010 \\
\hline Norte & 0,12 & 0,16 & 0,19 & 0,21 & 0,25 & 0,29 & 0,31 & 0,37 & 0,40 \\
\hline Nordeste & 0,12 & 0,18 & 0,23 & 0,30 & 0,50 & 0,58 & 0,66 & 0,73 & 0,81 \\
\hline Centro-Oeste & 0,14 & 0,19 & 0,23 & 0,30 & 0,34 & 0,36 & 0,43 & 0,46 & 0,49 \\
\hline Sudeste & 0,26 & 0,28 & 0,32 & 0,34 & 0,39 & 0,44 & 0,47 & 0,53 & 0,57 \\
\hline Sul & 0,29 & 0,32 & 0,38 & 0,45 & 0,58 & 0,69 & 0,73 & 0,80 & 0,87 \\
\hline Brasil & 0,21 & 0,24 & 0,29 & 0,33 & 0,43 & 0,50 & 0,55 & 0,60 & 0,66 \\
\hline
\end{tabular}

Fonte: Coordenação de Saúde Mental, Álcool e Outras Drogas/DAPES/SAS/MS, Instituto Brasileiro de Geografia e Estatística (2011)

Tabela 2 - Número de CAPS por tipo de ano (Brasil. 2002-2010):

\begin{tabular}{|c|c|c|c|c|c|c|}
\hline Ano & CAPS I & CAPS II & CAPS III & CAPSi & CAPSad & Total \\
\hline 2002 & 145 & 186 & 19 & 32 & 42 & 424 \\
\hline 2003 & 173 & 209 & 24 & 37 & 57 & 500 \\
\hline 2004 & 217 & 237 & 29 & 44 & 78 & 605 \\
\hline 2005 & 279 & 269 & 32 & 56 & 102 & 738 \\
\hline 2006 & 437 & 322 & 38 & 75 & 138 & 1010 \\
\hline 2007 & 526 & 346 & 39 & 84 & 160 & 1155 \\
\hline 2008 & 618 & 382 & 39 & 101 & 186 & 1326 \\
\hline 2009 & 686 & 400 & 46 & 112 & 223 & 1467 \\
\hline 2010 & 761 & 418 & 55 & 128 & 258 & 1620 \\
\hline
\end{tabular}

Fonte: Coordenação de Saúde Mental, Álcool e Outras Drogas/DAPES/SAS/MS (2011)

Verifica-se o crescimento exponencial, que passa de um indicador de 0,21 CAPS para cada 100.000 habitantes; a 0,66 CAPS para cada 100.000 habitantes, evidenciando a evolução e o desenvolvimento da política pública, demonstrando a continuidade da proposta.

Conforme descrição do art. $2^{\circ}$ da referida Portaria, constituem-se diretrizes essenciais para o funcionamento da Rede de Atenção Psicossocial, composta pelos CAPS, o respeito aos direitos humanos, a garantia de realização de atividades que estimulem a autonomia dos indivíduos, a promoção da equidade e 
combate ao preconceito, a garantia de qualidade no acesso aos serviços sob a lógica multidisciplinar e interdisciplinar, a atenção humanizada, desenvolvimento de estratégias de redução de danos, a ênfase em serviços de base territorial e comunitária, a participação dos usuários e de seus familiares, a promoção de estratégias de educação permanente e, finalmente, desenvolvimento da lógica do cuidado para pessoas com transtornos mentais e com necessidades decorrentes do uso de crack, álcool e outras drogas, tendo como eixo central a construção do projeto terapêutico singular.

A Rede de Atenção Psicossocial é constituída por Unidades Básicas de Saúde, Equipe de Consultório na Rua, Equipe de apoio aos serviços do componente Atenção Residencial de Caráter Transitório, Centros de Convivência, Centros de Atenção Psicossocial, SAMU, UPAs, Unidades de Recolhimento, Serviços de Atenção em Regime Residencial e Serviços Residenciais Terapêuticos; todos destinados à reabilitação psicossocial.

A redação do texto legal inova a extensão do cuidado com doentes mentais porque possibilita a maior aproximação entre as atividades realizadas e a presença dos familiares, reconhecendo a vulnerabilidade desse grupo de pessoas e identificando a necessária consolidação de direitos mais elementares, além de estabelecer parcerias indissolúveis entre sociedade civil e órgãos governamentais.

Trata-se de uma formulação de política pública que se inseriu definitivamente na agenda política, respaldada pela jurisdição e monitorada por serviços permanentes de avaliação de resultados. Assim, a qualidade dos serviços é periodicamente mensurada por meio de indicadores de efetividade e resolutividade da atenção, o que garante a continuidade dos serviços e a transparência das ações.

\section{CONCLUSÃO}

A aplicação de direitos humanos está diretamente vinculada ao exercício da liberdade e ao acesso aos expedientes constitucionais. A liberdade do indivíduo depende de sua ação, de sua noção quanto ao papel que desempenha no contexto social, quanto à importância que recai sobre a materialização de direitos.

O homem pode ser politicamente ativo quando detém inteligência sobre os fatos para discernir entre a concordância e a aquiescência sem reflexão, o que, invariavelmente, necessita da liberdade de escolha, oriunda da consciência sobre a condição de cidadão e que advém da concretização de um patamar mínimo de igualdade de acesso entre indivíduos, eminentemente, no que se refere ao exercício consciente de direitos.

Um problema de fundamental importância em relação à questão dos direitos humanos, em especial, no caso dos portadores de diagnósticos de doença mental, é o conflito entre o enfoque da Saúde Pública e a aplicação concreta dos direitos humanos.

O antagonismo ocorre porque, enquanto o primeiro se preocupa prioritariamente com a população de forma generalizada e sob a perspectiva do auxílio à coletividade, sem a análise das especificidades de cada 
indivíduo, o segundo se preocupa essencialmente com os casos excepcionais, atuando em nível individual para promover a igualdade substancial.

Existe uma contradição operacional, porque a norma indica inúmeras possibilidades de tratamento aos doentes mentais, de maneira harmônica e coerente às orientações internacionais, entretanto, deve-se perceber que a realidade extrajurídica e institucional brasileira nem sempre é compatível com a materialização de direitos, especialmente, quando se trata de uma categoria de indivíduos tradicionalmente esquecida pelas políticas públicas.

No caso do Hospital Psiquiátrico Colônia, em que pessoas com transtornos mentais eram mantidas em condições inóspitas, não havia espaço para que direitos humanos existissem. Não havia interesse político em fechar as portas do conhecido hospício que praticava maus-tratos e torturava pacientes de maneira sistemática, tampouco regulamentação específica que recriminasse tais condutas.

A omissão legitimava o sofrimento de tantos indivíduos que, nem sempre, sofriam com transtornos mentais. Com a Reforma Psiquiátrica, conduzida em consonância com a legislação internacional, o Brasil passou a vivenciar outro momento para a saúde psiquiátrica no país, porém, verifica-se que ainda são necessários contínuos esforços institucionais e governamentais para que a realidade da saúde mental seja efetivamente transformada em tratamento humanizado e propício à reinserção.

No Brasil, o caminho da adoção de políticas públicas tem evidenciado avanços, como a construção e desenvolvimento de Centros de Atenção Psicossocial, Residências Terapêuticas e auxilio-reabilitação psicossocial, para assistência, acompanhamento e integração social, fora das unidades hospitalares. São mudanças significativas na realidade da saúde psiquiátrica brasileira, que demonstram a necessidade de uma preocupação contínua com o tratamento digno dos indivíduos e o dever de vigília da jurisdição nacional pelo monitoramento de serviços permanentes e preocupação com a avaliação de resultados.

O atendimento humanizado é um dos enfoques mais elementares das políticas públicas de atenção à pessoa com transtornos mentais que, logo no acolhimento, são ouvidas e devidamente encaminhadas para a geração de um vínculo terapêutico baseado na construção de uma relação de confiança com os profissionais dos Centros de Atendimento e Centros de Referência, construindo-se estratégias individuais a partir da análise pormenorizada do caso concreto.

Não é possível conceber a existência de hospitais psiquiátricos como destinos finais de excluídos sociais, tampouco a conivência mórbida das instituições e dos profissionais de saúde quanto à situação dos pacientes com transtornos mentais.

A realidade dos hospitais psiquiátricos no Brasil nem sempre traduz os pactos de respeito aos direitos humanos, e é preciso constante vigília para que eventos que reduzem a dignidade humana não sejam 
considerados como fator comum. Quando se perde a razão, não se perde a humanidade, e é exatamente essa compreensão que a agenda governamental e a norma jurídica devem abranger para que sua aplicabilidade seja possível.

\title{
HUMAN RIGHTS OF PERSONS WITH MENTAL DISABILITIES: INSTITUTIONAL TREATMENT IN THE BRAZILIAN CONTEXT
}

\begin{abstract}
The aim of this research is to answer the following question: how should be the institutional treatment for the protection of human rights of people with mental disabilities in the Brazilian context? The research was based on descriptive-analytic method, with comparative analysis. This study also proposes the analysis on one of the most emblematic cases in the history of Brazilian psychiatric health; the Colônia Asylum, which received hundreds of forgotten and social marginalized ones, in a detention system whose treatment offered to patients never matched with the expected reintegration, disregarding the most elementary notions of human rights protection. We concluded that the protection of human rights in the Brazilian psychiatric context depends on the implementation of consistent and continuous public policies, and the new interpretation of the law, transcending the symbolic perspective of rhetoric duties.
\end{abstract}

Keywords: Public Policy; Person with mental disabilities; Human rigths; Colônia Asylum; Institutions.

\section{BIBLIOGRAFIA}

ALVES, Cleber Francisco; PIMENTA, Marília Gonçalves. Acesso à justiça em preto e branco: retratos institucionais da Defensoria Pública. Rio de Janeiro, Lúmen Júris, 2004.

ARBEX, Daniela. Holocausto brasileiro: 60 mil mortos no maior hospício do Brasil. São Paulo, Geração Editorial, 2013.

BRASIL. (1988). Constituição da República Federativa do Brasil. Brasília, DF, Senado.

Ministério da Saúde. Secretaria de Atenção à Saúde. DAPE. Coordenação Geral de Saúde Mental. (2015). Reforma psiquiátrica e política de saúde mental no Brasil. Documento apresentado à Conferência Regional de Reforma dos Serviços de Saúde Mental: 15 anos depois de Caracas. OPAS. Braślia, novembro de 2005. Disponível em: < http://bvsms.saude.gov.br/bvs/publicacoes/Relatorio15_anos_Caracas.pdf>. Acesso em: 13 jul. 2016.

Secretaria de Direitos Humanos da Presidência da República do Brasil. Direitos para todos. 2009. Disponível em: <http://www.sdh.gov.br/assuntos/direito-para-todos>. Acesso em: 10 mar. 2016. Senado.

Código Penal brasileiro. Decreto-Lei n ${ }^{\circ}$ 2.848, de 7 de dezembro de 1940. Brasília, Distrito Federal,

Lei n $^{\circ}$ 10.216, de 6 de abril de 2001. Brasília, Distrito Federal, Senado.

DOUZINAS, Costas. The end of human rights. Tradução: Luzia Araújo. São Leopoldo, Unisinos, 2009. 
FOUCAULT, Michel. Vigiar e Punir. 40 ed. Petrópolis, Vozes, 2012.

KANT, Imanuel. Fundamentação da metafísica dos costumes e outros escritos. São Paulo, Martin Claret, 2004.

LINDBLOM, Charles E. Muddling through. In: Políticas públicas e desenvolvimento: bases epistemológicas e modelos de análise. Francisco G. Heidemann e José Francisco Salm, (Org.). Brasília, Editora Universidade de Brasília, 2009.

MASIERO, André Luis. (2010). A lobotomia e a leucotomia nos manicômios brasileiros. Disponível em: <http://www.scielo.br/scielo.php>. Acesso em: 09 ago. 2016.

MINISTÉRIO DA SAÚDE. (2009). Saúde mental no SUS: os Centros de atenção Psicossocial. Disponível em: $<$ http://www.ccs.saude.gov.br/saude_mental/pdf>.Acesso em: 07 jul. 2016.

MIRANDA, Jorge. Manual de direito constitucional. Portugal: Coimbra Editora, 1993.

PEREIRA, André Gonçalves; QUADROS, Fausto. Manual de direito internacional público. 3. ed. Lisboa: Almedina, 2002.

RICOEUR, Paul. Tempo e narrativa. São Paulo: Papirus, 1995.

REALE, Miguel. Lições preliminares de direito. 27 ed. São Paulo: Saraiva, 2012.

SANT'ANNA, Denise Bernuzzi. Corpos de passagem: ensaios sobre a subjetividade contemporânea. São Paulo: Estação Liberdade, 2001.

SARLET, Ingo Wolfgang. Dignidade da pessoa humana e direitos fundamentais na Constituição Federal de 1998. Porto Alegre: Livraria do Advogado Editora, 2007.

SILVEIRA, Vladmir Oliveira da; ROCASOLANO, Maria Mendez. Direitos humanos: conceitos, significados e funções. São Paulo: Saraiva, 2010.

Trabalho enviado em 11 de agosto de 2016.

Aceito em 05 defevereiro de 2017. 